\title{
The widening political divide over science
}

\author{
Philip N. Cohen \\ University of Maryland \\ pnc@umd.edu
}

August 22, 2020

\begin{abstract}
Gauchat (2012) reported that political conservatives in the United States lost confidence in the scientific community from the 1970s to 2010, but political liberals and moderates did not. As a result, a political divide opened up so that by 2010 conservatives had the lowest level of confidence in science. This analysis extends the trends through the 2018 General Social Survey (GSS). I find that political conservatives, Republicans, and Americans who attend religious services regularly, all report falling levels of confidence in the scientific community. Further, for the period 2012-2018, educational attainment, for conservatives, is not associated with increased levels of confidence in science, except at the graduate degree level (and even there confidence is lower among conservatives). In the Trump era, with an assault on facts and truth defining the president and his party, the growing political divide over confidence in science seems likely to further undermine political processes that rely on common knowledge and understanding. This updates the original 2018 version of this paper with the 2018 GSS data.
\end{abstract}

Stata code and the log file for this analysis are available on the Open Science Framework here: https://osf.io/293z7/. 
Political divisions over confidence in science are corrosive to democratic processes, because the lack of shared trust undermines the capacity for constructive policy engagement. In contemporary political discourse, this divide is apparent in debates over a number of key issues, of which the COVID-19 pandemic is the most immediate (Thorp 2020), with wide and growing partisan differences among the public appearing with regard to confidence in medical scientists, the threat posed by the pandemic, social distancing, and the importance of testing (Funk and Tyson 2020). Climate change is also among the most prominent divides, with conservative media and political leaders attacking the credibility of scientists as a way to discredit scientific findings they find inconvenient (Carmichael, Brulle, and Huxster 2017; McCright and Dunlap 2011).

Gauchat (2012) reported that political conservatives in the United States lost confidence in the scientific community from the 1970s to 2010, but political liberals and moderates did not. As a result, a political divide opened up so that by 2010 conservatives had the lowest level of confidence in science. Gauchat also found that trust in science declined among Americans who attend religious services frequently, which implies a broader foundation than simple partisan political influences. He concluded the evidence supports neither a cultural ascendency pattern, in which trust in science grows over time in modern society, nor an alienation pattern of generally declining trust. Gauchat's analysis also undermined a deficit model, in which misttrust in science follows from low levels of formal education, because highly educated conservatives led the decline in trust (see also McCright and Dunlap 2011). Thus, he argued for a politicization thesis:

“Conservatives' distrust is attributable to the political philosophy and intellectual culture accompanying the new right and the increased connection between scientific knowledge and regulatory regimes in the United States, the latter of which conservatives generally oppose.” (Gauchat 2012:171-2)

Although perhaps attributable to the (former) new right, this tension has grown during the (newer right) presidency of Donald Trump, who was elected on the promise of disengaging from international climate cooperation, after calling climate change a "hoax" (Wong 2016). After assuming the presidency, when asked whether he accepted the judgment of government climate scientists, Trump said that climate scientists "have a very big political agenda" (CBS 60 Minutes 2018), which undermines the legitimacy of the scientific enterprise. In response to a federal interagency report on climate change, Republican strategist Rick Santorum claimed scientists are corrupt: 
"Look, if there was no climate change we'd have a lot of scientists looking for work. The reality is that a lot of these scientists are driven by the money they receive ... they receive it from people who support their agenda, and that I believe is what's really going on here." (CNN 2018)

By this logic, treating the scientific establishment as suspect is a rational response to the politicization of science by liberals. Thus, Cofnas, Carl, and Woodley (2018) responded to Gauchat's (2012) findings by attributing the partisan divergence to the politicization of science by liberals, and especially social scientists, who "have increasingly adopted a liberal activist stance" (p. 135). In their view, conservatives do not distrust science itself, but rather the (liberal) scientific establishment. In response to the anti-science (or anti-scientist) stance of the contemporary right, anti-Trump activists have embraced a positive attitude toward science and scientists (Fisher 2017; Ross et al. 2018).

In this context, I extend Gauchat's (2012) paper through the 2018 edition of the General Social Survey. I find that partisan, ideological, and religious divisions over confidence in science have widened since 2010 .

\section{Data and methods}

I use the General Social Survey (GSS) from 1974 to 2020 (Smith et al. 2020), analyzing responses to a question on confidence in the scientific community, which has been used in all editions of the survey (except 1985) during this period. In the years 1984 and 1988-2020 the question was asked of two-thirds of the respondents. The question (CONSCI) asked:

"I am going to name some institutions in this country. As far as the people running these institutions are concerned, would you say you have a great deal of confidence, only some confidence, or hardly any confidence at all in them? [Item:] Scientific community."

I examine the likelihood of expressing "a great deal" of confidence in the scientific community, versus "only some" and "hardly any" (the latter two responses combined). To test the widening social divide over this attitude, I use political views (liberal, moderate, or conservative), party identification (Democrat, Independent, and Republican), and frequency of religious attendance (never, less than once a month, once a month of more). In addition, I control for educational attainment, age, sex, race/ethnicity, and self-identified social class.

In the first part of the analysis I test for diverging trends in confidence in science by political views, party identification, and religious attendance, from 1974 to 2018. Next, I examine the period after 2010 (when Gauchat's 
analysis ended), and specifically address whether educational difference in this attitude differ for conservatives versus the balance of the population.

I use religious service attendance to capture religious influences, as Gauchat (2012) did. Subsequent analysis by Sherkat (2017) shows that the religious effect is driven by sectarian Protestants and those who believe the Bible is the literal word of God. My focus is not on these religious differences. Noy and O'Brien (2018) examine attitudes toward science by race/ethnicity and gender; although I control for race/ethnicity and gender, I do not pursue these interactions here. $^{1}$

My models are not identical to those used by Gauchat (2012), but the patterns they reveal for the period before 2010 are the same. Differences from Gauchat's model include: he controls for family income, while I control for selfdefined social class; he uses enters religious service attendance as a linear function of seven categories, while I collapse it into three categories and enter them as dummy variables; he controls for party identification while assessing the effects of political views, while I enter them in separate models; he enters both years of schooling and degrees completed, while I use only the latter; he uses age and its square, while I enter age in decades. Finally, Gauchat enters time as a linear function (years), with categorical variables associated with presidential terms, while I use decade categories. Gauchat (2012) does not mention whether he used GSS weights in his analysis. After showing descriptive statistics unweighted, I use the WTSSALL weight with controls for design effects for all multivariate analysis (using VSTRAT and VPSU). The overall sample size is 36,785 . Variables in the analysis are shown in Table 1.

I present the entire sequence for consistency, and then focus on 2012 to 2018 . The first multivariate logistic model interacts time periods with political views to predict "great deal of confidence" in the scientific community, with controls for religion and the other variables mentioned. The second model repeats that structure, but with party identification instead (excluding 1.5 percent cases with "other" party specified). The third model interacts time with the frequency of religious attendance, with a control for party identification. For time periods, I group samples by decade for the 1970s, 1980s, 1990s, and 2000s. The final model includes only the 2012, 2014, 2016, and 2018 surveys $(N=5,989)$, and tests for the interaction between educational attainment and conservative views.

\section{Results}

\footnotetext{
${ }^{1}$ Black distrust of science in particular is associated with medicine, and the Tuskegee experiment, which had long-term effects on medical care and practices (Alsan, Marcella, and Marianne Wanamaker 2018).
} 
Figure 1 shows the trends in percentage expressing a great deal of confidence in the scientific community, extending Gauchat's (2012:175) Figure 1. The annual percentages are represented by dots, with the lines reflecting averages over three survey administrations for smoother presentation. After 2010, there was a year of convergence between liberal and conservative attitudes in 2012, followed by a sharp divergence. In 2018 the gap between liberal and conservative reached a peak of 18.6 percentage points.

To present the multivariate logistic regression results for time trends I will illustrations of predicted probabilities using marginal standardization. These show predicted probabilities at a weighted average of values reflecting the distribution of other variables in the sample (Muller and MacLehose 2014), with 95 percent confidence intervals. (The full results are in the log file associated with this project.)

Figure 2 shows Gauchat's main finding: trust in science, adjusted for covariates, remained mostly flat for liberals and moderates (with the former at a higher level), while falling steeply for conservatives. This is also consistent with the unadjusted trends in Figure 1. The final period, 2010-2018, continues this trend, with conservatives falling further below liberals in their confidence in the scientific community. Figure 3 repeats this model, except using party identification instead of political views. Here Republicans, who had the highest levels of confidence in the 1980s, fall to the lowest level of confidence by the final period, 2010-2018.

Figure 4 shows the trends for religious service attendance. Those who never attend religious services, and those who attend less than once per month, end the survey period very close to where they began it in terms of confidence in the scientific community. In contrast, those who attend services once per month or more, who in the 1970s already demonstrated lower levels of confidence, by the 2010s have diverged dramatically from the rest of the population to newly low levels of confidence.

In summary, the multivariate time trend analysis extends the findings of Gauchat (2012), showing continued growth of the ideological gap - by political views, party identification, and religious observance - in how much Americans trust the scientific community. For the years 2010-2018, political conservatives, Republicans, and people who attend religious services once per month or more, demonstrate substantially lower adjusted probabilities of expressing a great deal of confidence in the scientific community.

Finally, Table 2 and Figure 5 show analysis from the 2012-2018 period. Using an interaction between education and conservative views, the final model tests whether education has a weaker association with confidence in the scientific 
community for conservatives in the latest period. The interaction shows that negative effects of conservative political views on each level of education, with the interaction mostly canceling out the effect of a bachelor's degree ( +.889 for the degree, -.613 for conservative views). The relationship is illustrated in Figure 5, which shows a significant positive effect of education on conservatives only at the graduate degree level. This is consistent with the argument that conservative ideology is relatively impervious to educational intervention on the question of trusting the scientific community.

The model for the latest period, in Table 2, also shows that older people, lower- and working-class people, women, and Blacks all are less likely to express great confidence in the scientific community - holding constant political views and religious service attendance.

\section{Conclusion}

Since the 1970s, American conservatives, Republicans, and those who frequently attend religious services have dramatically shifted away from expressing confidence in the scientific community. This was reported by Gauchat (2012), and this analysis confirms the division continued to grow through 2018. This undermines the notion of modernity as an era of increasing trust in science; yet it is not part of a general mistrust of science, because it is not apparent among those with less conservative views. As the divide widens, it may become easier for right-wing political leaders to use mistrust of science to mobilize conservative skeptics for partisan ends. And appeals to science may grow (even) less effective as a means for persuading conservatives of the benefits of liberal policy positions. The politicization thesis gains further support here.

Although Donald Trump's appeal is often linked to working-class White Americans, lack of confidence in the scientific community reaches high up the educational hierarchy among conservatives as well. (Clearly mistrust of science is not enough to spur devotion to Trump, as Blacks have low levels of confidence in the scientific community while not supporting Trump.) Authoritarian leaders have historically relied on anti-intellectual messages to unify their bases of support (Stanley 2018). Although Trump did not bring mistrust of science into the conservative mainstream, one of his defining features is a relentless assault on facts and truth (Kakutani 2018). The trends described here suggest the political ground is fertile for such an approach, and the experience of the COVID-19 pandemic, in which public health compliance emerged as a major partisan fissure (Alcott et al. 2020), showed its potential consequences. 


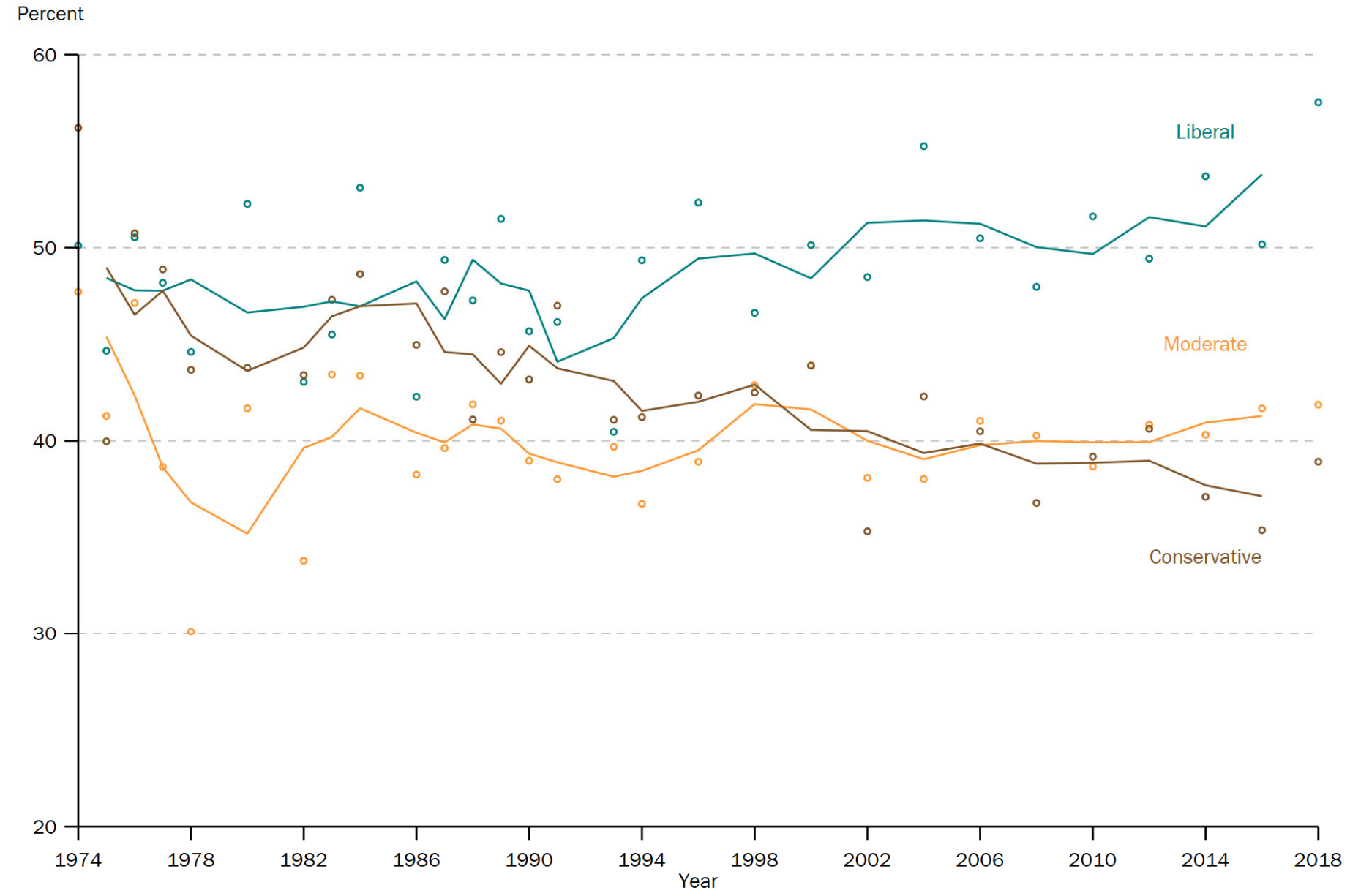

Figure 1. Percent expressing a great deal of confidence in the scientific community, by political views: 1974-2018. With three-survey averages 
Probability of confidence

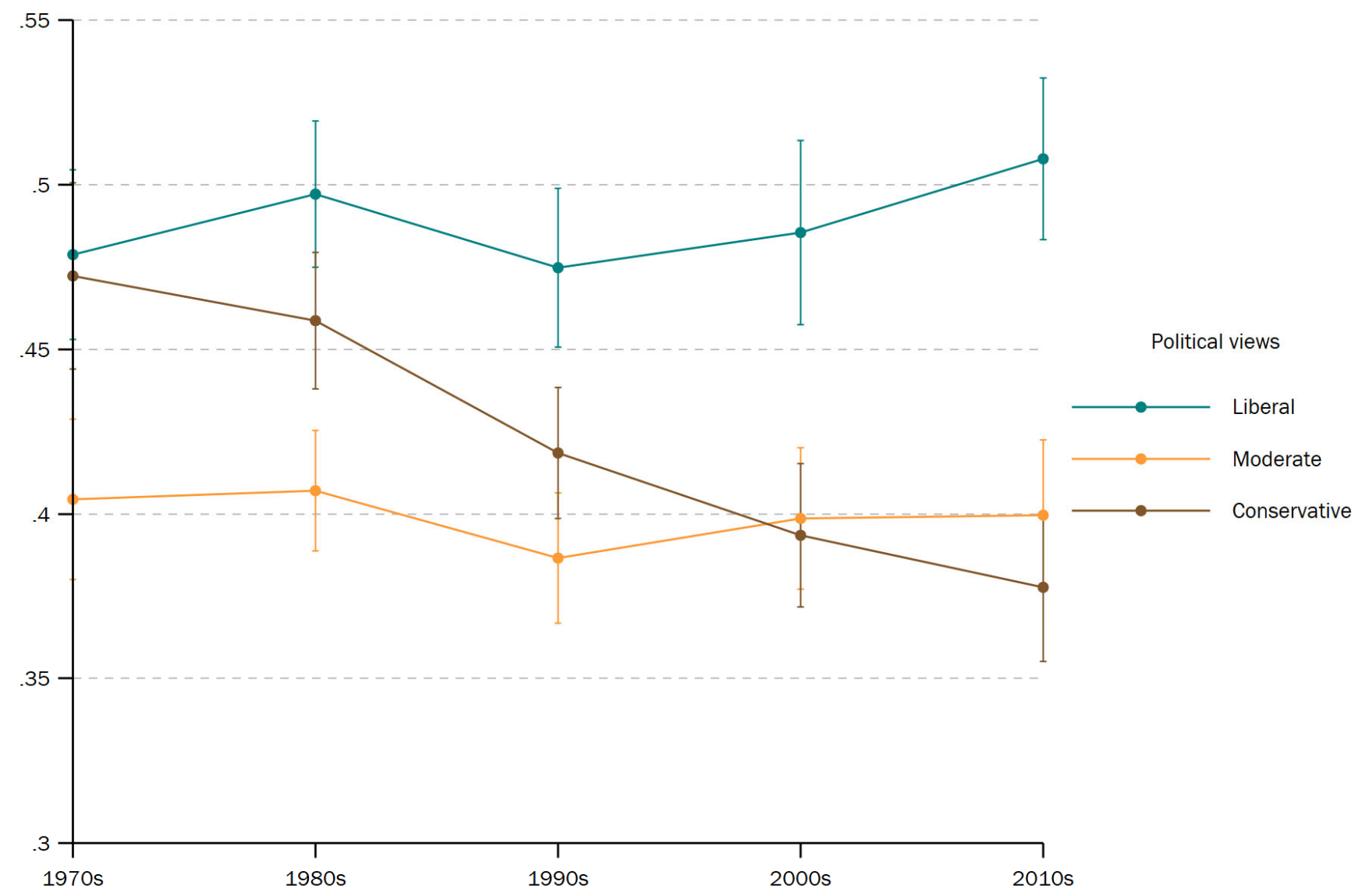

Figure 2. Probability of confidence in the scientific community, by political views: 1974-2018. Marginal probabilities, controlling for age, education, class, sex, religious attendance, and race. 
Probability of confidence

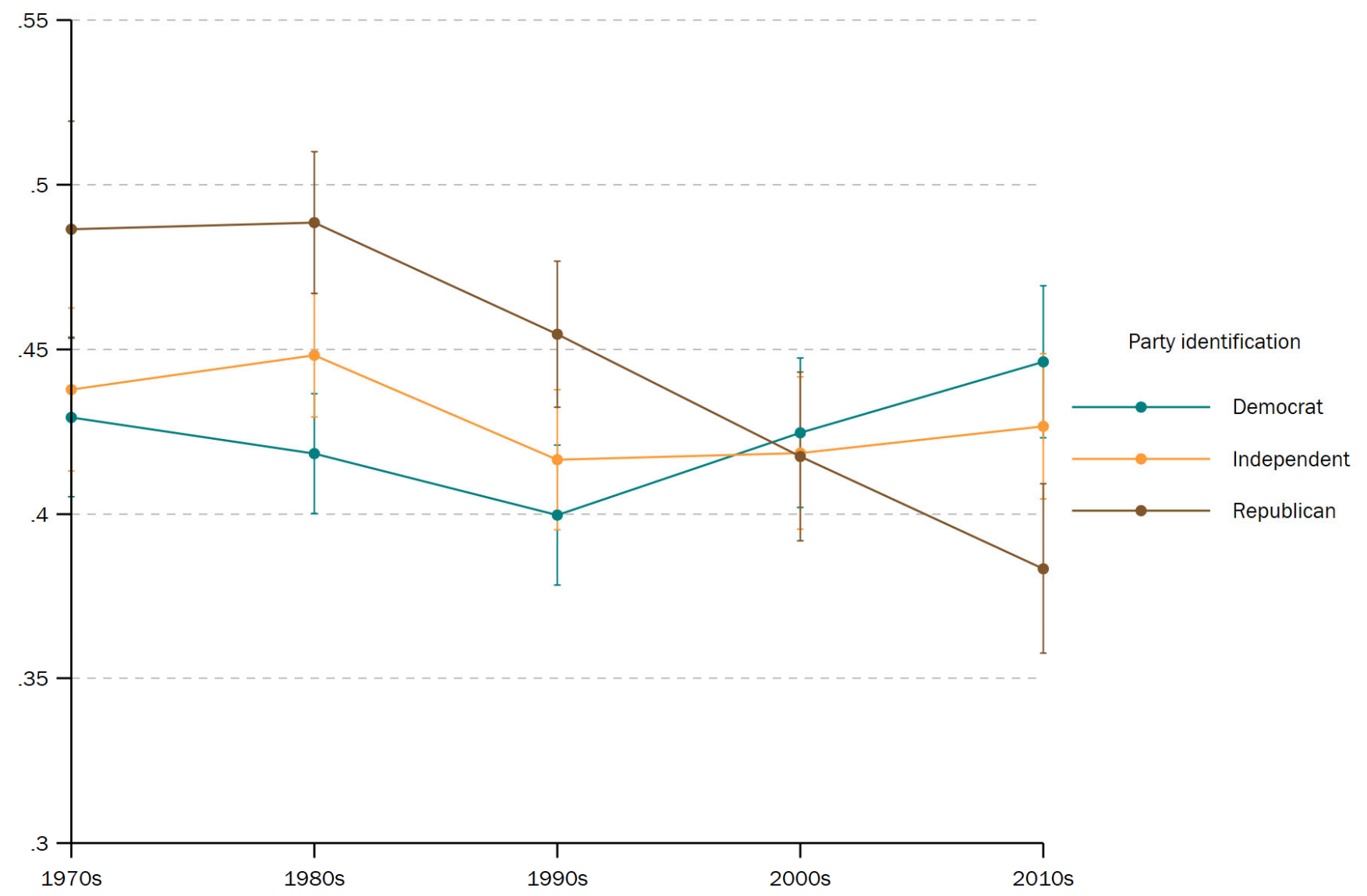

Figure 3. Probability of confidence in the scientific community, by party identification: 1974-2018. Marginal probabilities, controlling for age, education, class, sex, religious attendance, and race. 
Probability of confidence

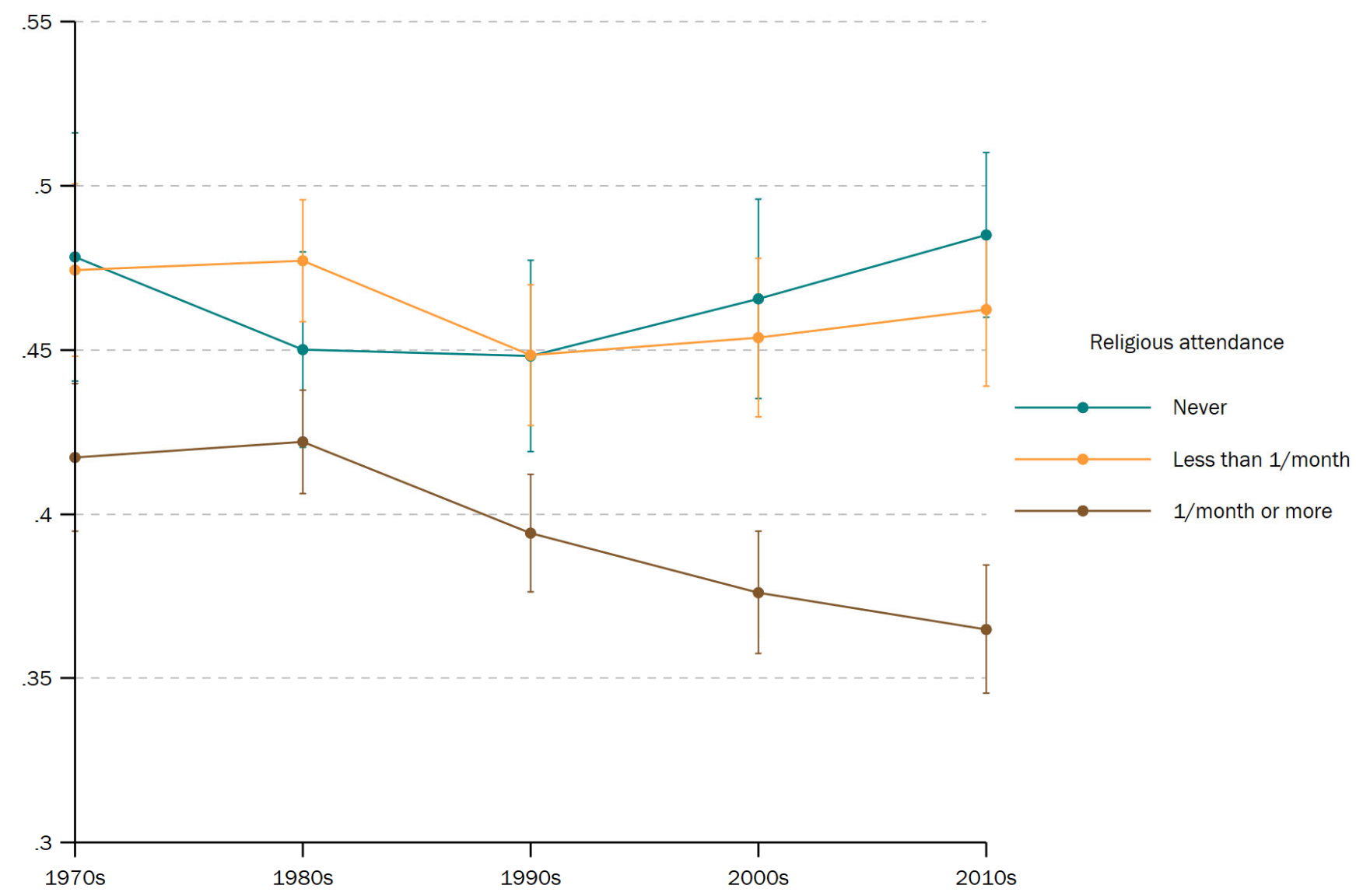

Figure 4. Probability of confidence in the scientific community, by religious attendance: 1974-2018. Marginal probabilities, controlling for age, education, class, sex, religious attendance, and race. 
Probability of confidence

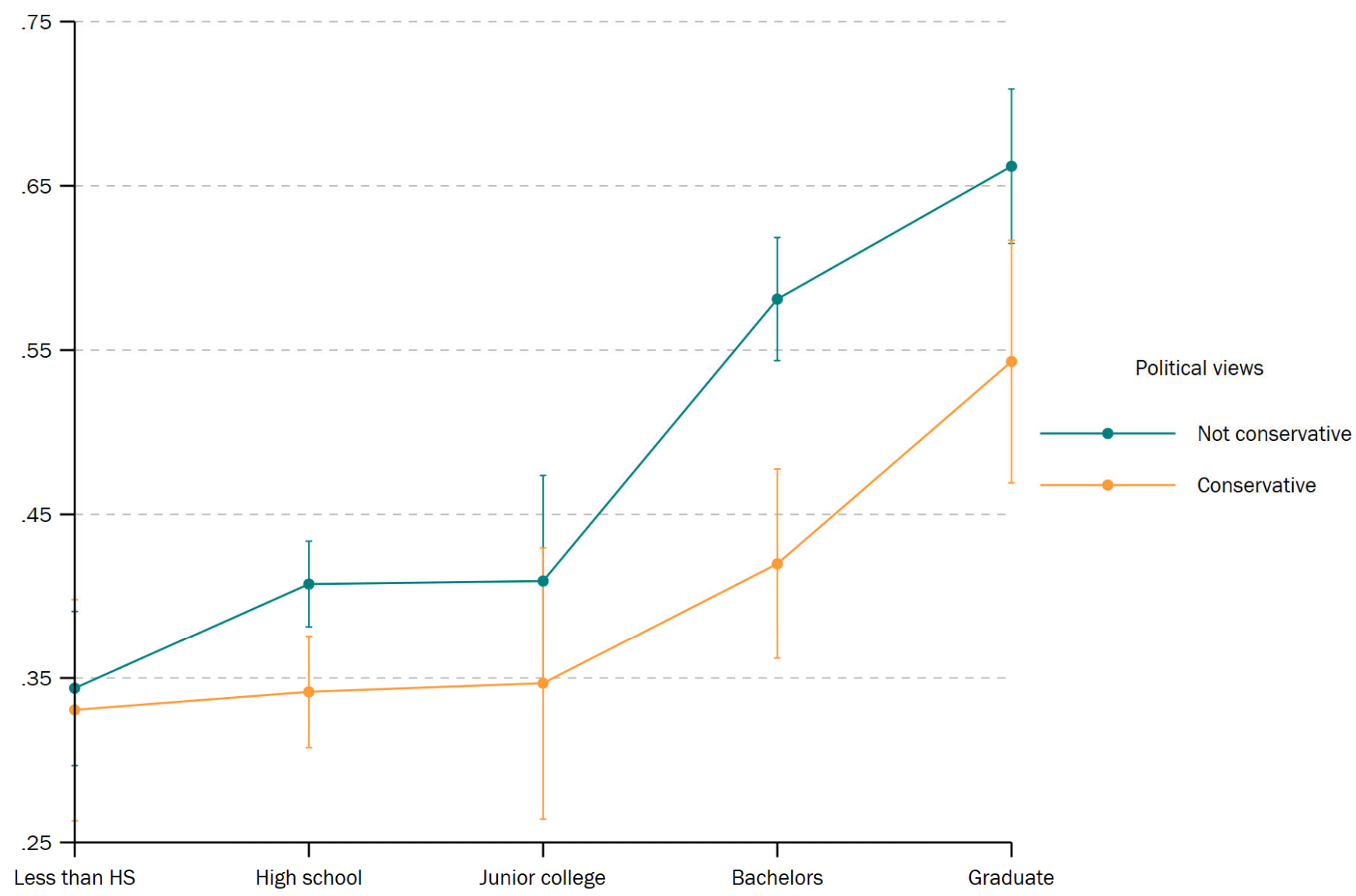

Less than HS

High school

Junior college

Bachelors

Graduate

Figure 5. Probability of confidence in the scientific community, by education and political views: 2012-2018. Marginal probabilities, controlling, for age, education, class, sex, religious attendance, and race. 
Table 1. Variables in the analysis

Great confidence in the scientific community No

Period

$1970 \mathrm{~s}$

17.5

$1980 \mathrm{~s}$

24.8

$1990 \mathrm{~s}$

20.9

2000-2010

17.1

2012-2018

19.7

Political views

Liberal $\quad 27.8$

Moderate $\quad 38.2$

Conservative $\quad 34.1$

Age

$18-29$

21.6

$30-39$

22.1

40-49

18.1

50-59

$60+$

15.4

22.8

Educational degree

Less than HS $\quad 18.8$

High school $\quad 52.1$

Junior college $\quad 5.8$

Bachelors $\quad 15.6$

Graduate $\quad 7.6$

Social class

Lower $\quad 5.9$

Working $\quad 45.4$

Middle $\quad 45.4$

Upper $\quad 3.2$

Sex

Male $\quad 45.6$

Female $\quad 54.4$

Race/ethnicity

White $\quad 79.3$

Black $\quad 13.3$

Other $\quad 3.1$

Hispanic $\quad 4.3$

Religious service attendance

Never $\quad 17.5$

Less than $1 /$ month $\quad 34.1$

$1 /$ month or more $\quad 48.4$

$N=36,785$. Unweighted. 
Table 2. Logistic regression coefficients for great confidence in scientific community on

political views and education, 2012-2018

Education

\begin{tabular}{lrr} 
Less than high school & ref & \\
High school & .231 & \\
Junior college & .301 & \\
Bachelors & .889 & $*$ \\
Graduate & 1.229 & $*$ \\
\hline
\end{tabular}

Conservative

$-.018$

Education and conservative

High school * Conservative $\quad-.216$

Junior college * Conservative $\quad 0.198$

Bachelors * Conservative $\quad-.613$ *

Graduate * Conservative $\quad-.446$

Age

$18-29$ ref

30-39 -.357

$40-49-.398 *$

$50-59-530 *$

$60+-.520 *$

Social class

Lower ref

Working $\quad .004$

Middle $\quad .286$

Upper $\quad .821$ *

Female

$-.301 *$

Race / ethnicity

White ref

Black - -.606

Hispanic $\quad-.048$

Other $\quad .042$

Religious attendance

Never ref

Less than $1 /$ month $\quad-.095$

$1 /$ month or more $\quad-.356$

Year

\begin{tabular}{lrr} 
& 2012 & ref \\
& 2014 & -.017 \\
& 2016 & -.043 \\
& 2018 & .042 \\
\hline Constant & & .022 \\
$N$ & & 5,989 \\
\hline
\end{tabular}

$* \mathrm{p}<0.01$ 


\section{References}

Allcott H, Boxell L, Conway JC, Gentzkow M, Thaler M, Yang DY. Polarization and Public Health: Partisan Differences in Social Distancing during the Coronavirus Pandemic. National Bureau of Economic Research; 2020 Apr. Report No.: 26946. doi:10.3386/w26946

Alsan, Marcella, and Marianne Wanamaker. 2018. "Tuskegee and the Health of Black Men." The Quarterly Journal of Economics 133 (1): 407-55. https://doi.org/10.1093/qje/qjx029.

Carmichael, Jason T., Robert J. Brulle, and Joanna K. Huxster. 2017. “The Great Divide: Understanding the Role of Media and Other Drivers of the Partisan Divide in Public Concern over Climate Change in the USA, 2001-2014." Climatic Change 141 (4): 599-612. https://doi.org/10.1007/s10584-0171908-1.

CBS 60 Minutes. 2018. "President Trump on Christine Blasey Ford, His Relationships with Vladimir Putin and Kim Jong Un and More.” October 15. https://www.cbsnews.com/news/donald-trump-fullinterview-60-minutes-transcript-lesley-stahl-2018-10-14/.

CNN. 2018. "Santorum Claims Climate Scientists ‘Driven by Money.” November 25. https://www.cnn.com/videos/politics/2018/11/25/sotu-panel-pt-2.cnn.

Funk, Cary, and Alec Tyson. 2020. "Partisan Differences Over the Pandemic Response Are Growing." Pew Research Center Science \& Society. June 3. https://www.pewresearch.org/science/2020/06/03/partisan-differences-over-the-pandemic-responseare-growing/.

Gauchat, Gordon. 2012. "Politicization of Science in the Public Sphere: A Study of Public Trust in the United States, 1974 to 2010.” American Sociological Review 77 (2): 167-87.

Kakutani, Michiko. 2018. The Death of Truth: Notes on Falsehood in the Age of Trump. 1st Edition edition. New York: Tim Duggan Books.

McCright, Aaron M., and Riley E. Dunlap. 2011. "The Politicization of Climate Change and Polarization in the American Public's Views of Global Warming, 2001-2010.” The Sociological Quarterly 52 (2): 155-94. https://doi.org/10.1111/j.1533-8525.2011.01198.x.

Muller, Clemma J, and Richard F MacLehose. 2014. "Estimating Predicted Probabilities from Logistic Regression: Different Methods Correspond to Different Target Populations." International Journal of Epidemiology 43 (3): 962-70. https://doi.org/10.1093/ije/dyu029.

Noy, Shiri, and Timothy L. O’Brien. 2018. “An Intersectional Analysis of Perspectives on Science and Religion in the United States." The Sociological Quarterly 59 (1): 40-61. https://doi.org/10.1080/00380253.2017.1383141.

Smith, Tom W., Michael Davern, Jeremy Freese, and Michael Hout. 2020. General Social Surveys, 19722020. Chicago: NORC at the University of Chicago. 
Stanley, Jason. 2018. How Fascism Works: The Politics of Us and Them. New York: Random House.

Thorp, H. Holden. 2020. “Persuasive Words Are Not Enough.” Science 368(6498):1405-1405.

Wong, Edward. 2017. "Trump Has Called Climate Change a Chinese Hoax. Beijing Says It Is Anything But.” The New York Times, December 22. https://www.nytimes.com/2016/11/19/world/asia/chinatrump-climate-change.html. 